\title{
After 20 years, some reflections and farewell!
}

Raanan Gillon Imperial College, University of London

Gripped by an odd blend of excited liberation at forthcoming retirement and the sadness of impending loss, I've been skimming past issues of the JME looking for themes, for developments, for ideas, for this valedictory editorial after twenty years as its editor. A few may be worth offering. First some general impressions. The enthusiasm that medical ethics still seems to inspire in those who write about it leaps out of the JME's pages. So does the enormous breadth of the subject, along with the multi-, inter- and trans-disciplinarity from which it is approached. Doctors, philosophers, theologians and lawyers; bishops and rabbis, social scientists and government officials; patients and patient representatives; professors and students, and many many more are in our pages, advocating and arguing vigorously: and they have been doing so from an ever increasing number of countries.

One of the most agreeable benefits for me has been the friendships, intellectual with many and personal with quite a few, with people from these various disciplines, occupations and perspectives, cultures and countries, that medical ethics has facilitated and it was good to find so many of these friends communicating with me as I browsed through the journal's pages. Let me also take the opportunity of thanking all my friends and colleagues who have helped me edit this journalauthors, book reviewers, letter writers, referees (so exceedingly important and unsung and unrewarded a group), editorial and advisory board members, especially our wise chairman, Tom Oppe, members of the BMJ special journals division, and all those who actually make the journal appear once the editor has chosen its contents. While I don't have space to name all whom I thank, particular tribute is due to the small team who have been with me for eighteen or more of my editorial years, Ann Lloyd, our excellent technical editor (in function if not title the production editor of the journal), Maureen Bannatyne my oh so thorough editorial assistant (who has saved me and the journal from many a slip), and Tony Hope, associate editor, now professor of medical ethics at Oxford, whose quiet and constant and modest help and advice has been invaluable. (I invited him to write a second editorial in this issue because he too is leaving the journal. Having, as editor, read it, only my total immodesty prevented me from cutting most of it - instead I'd like to thank him also for his excessively kind words, and invite him to write my obituary - though perhaps he has and they are).To these three colleagues and friends, special thanks. Thanks too to our recently recruited book reviews editor, Mike Parker, a rising star in the bioethics firmament.

Another pleasure that I derived from browsing through the journal was to find that on the whole my declared intention to present the subject in "clear jargon-free English accessible to any intelligent reader" has been fulfilled-though alas with some exceptions. Apart from its successful provision of a forum for reasoned discussion of the entire range of medical ethics issues some other achievements of the journal have given me particular pleasure. One of the most satisfying has been its journal's continuing involvement with clinical practice and its ethical problems - especially through our intermittent "at the coal face: medical ethics in practice" series. I confess that one of those coal face articles once again gave me goose pimples as I re-read it - the one from a doctor looking after an unconscious patient who had been shot in the head describing the menacing hospital visits from the patient's gangster father and his veiled threats against the doctor's own children should his son not survive. On that occasion my insistence on changing the writer's name-and other details-was designed to ensure anonymity not simply to protect patient confidentiality but also so as not to have the possible retaliatory assassination of the writer on my conscience! (Conversely, perhaps the funniest contribution I came across was Richard Benthall's 1992 paper on happiness as a psychiatric disorder). However, also in the context of the journal's clinical ethics involvement, one of my greatest regrets has been my failure to continue Roger Higgs's excellent pioneering "case conference" series .

A further cause of satisfaction has been the journal's involvement with medical ethics education, especially for medical students. Ever since my own medical student days I have rued the lack of medical ethics education in the medical curriculum. Indeed when, on qualifying, I asked my eminent professor of medicine if I could do a doctorate in medical ethics I was given a half-hour scolding for 
the very idea that one could study medical ethics-it was something that one learned by doing medicine, he assured me, adding that if perchance the subject could be studied it would need to be studied by doctors with many years of clinical experience; and that if by some yet more remote chance it could be studied by a young doctor, that doctor certainly shouldn't be me. Even in 1981 when I took over as editor of the journal, some 17 years after this enlightened opinion had been delivered, the idea of formal medical ethics education was still anathema for many traditional medical school teachers, although by this time a small cadre of medical ethics enthusiasts were occupying positions of influence in medical schools. Many of these had been nurtured in their enthusiasm from the 1960s onwards by the founder of the JME, Ted Shotter, now Dean of Rochester Cathedral. Ted, then a young Church of England chaplain, had developed ethics study groups for medical students in most British medical schools, and then, as those students had become doctors, a "senior" study group, the Society for the Study of Medical Ethics, subsequently the Institute of Medical Ethics.Ted was very keen that the subject should be studied by everyone involved in medicine, medical and nursing professionals, students, patients and others, and that there should be no religious or other dictats impeding its development. (When I was appointed editor, replacing Alastair Campbell, another Christian cleric, I wondered how I, an atheist Jew-though admittedly schooled at Christ's Hospital-could fulfil Alastair's and Ted's high hopes: Ted, winking, assured me that I was a Godsend!)

Anyway it was good to see the gradual acceptance of medical ethics education in medical schools reflected in the journal's pages. A 1981 editorial urged a working party to look at the "prima facie case for formal and probably compulsory teaching of analytic medical ethics within the medical curriculum"; a 1985 issue reported the General Medical Council's (GMC) conference on ethics education in medical schools; in 1987 a symposium on teaching medical ethics described various approaches, and an editorial outlined the Institute of Medical Ethics influential Pond Report, edited by Kenneth Boyd, the IME's director of research. Following the GMC's Tomorrow's Doctors requirement in 1993 that medical ethics and law be taught in medical schools as a core subject (ie compulsory for all) - a requirement at that time widely ignored-we published another symposium on teaching medical ethics in 1994, which included Tony Hope's and Bill Fulford's account of their impressive Oxford Practice Skills Programme, now internationally emulated. In 1996 an editorial recalled American experiences in trying to develop a core curriculum for medical ethics education in medical schools, proposed a similar exercise in the $\mathrm{UK}$ and floated some ideas for the (somewhat different) content of a possible British core curriculum for medical ethics and law. Then in June 1998 we published the consensus statement of the large majority of UK medical school teachers of medical ethics and law proposing the contents of a core curriculum for medical ethics and law in medical education, now apparently widely accepted - at least in principle - in UK medical schools and apparently of some interest in other parts of the world too.

A further source of pleasure and pride was the recent birth of our sister journal-or "edition"Medical Humanities - for there is much more than medical ethics to the "human side of medicine"a side of medicine that needs major and sustained encouragement and nurturing in the face of the exponential growth in recent years of its scientific, technical and managerial sides, and their demands on a doctor's time, energy and orientation

I am pleased to - though sceptically so-at the journal's position in recent years as the medical ethics/bioethics/biomedical ethics journal with the highest impact factor in the world, as measured by the Institute for Scientific Information. While I cannot pretend to be convinced of the intellectual importance of impact factors I have been delighted to be able to boast that we have the highest impact factor in our field, especially as the academic world now seems so obsessed with these figures.

\section{Reasoned discussion}

I am also relieved that in our pursuit of reasoned discussion of medical ethics, the journal has succeeded in avoiding the vituperative and blameladen approach to medical ethics that infects some of its exponents. It was for rejecting, in a 1991 editorial, what I considered to be unjustified abuse that I and the British Medical Association (who had bought a half share in the journal two years previously) were sued for libel. I re-read with wry amusement the statement I agreed to publish in the journal in order to settle the libel claim, confirming that when I had written "scurrilous" to describe abusive comments that I had been criticising I had not meant that the abuse had been obscene (yes, that is one of the meanings of scurrilous!) but that I had meant that the abuse was in my view "grossly offensive". However, I still rather regret the opportunity that had then been looming of being helped to defend myself in court by that great libel lawyer, the late George Carman QC.

There is of course a place for blame, and possibly even for abuse, in ethics: but on the whole the material that those interested in medical ethics are considering is not clearly and unequivocally wrong, bad, evil, and thus blameworthy. Instead it usually involves conscientious disagreements and uncertainties about its moral status, and requires reasoned analysis and argument, and a thorough understanding of opposing views, rather than gutresponse condemnation and abuse of those with whom one disagrees: it has been a pleasure to reject such material when submitted to the journal!

Rejection of abusive style has in no way necessitated omission of lively debates and controversies. Among those from the 1980s that struck me in my review were debates about: the ethics of psychosurgery; allocation of scarce resources by lottery for patients deemed to be in equal medical need; the 
treatment of severely handicapped neonates; the harm allegedly inflicted by research ethics committees; advertising by doctors; the professional role of doctors and whether or not they should strike; the use of animals in medical research; the relationship of doctors and nurses; abortion and sterilisation for mentally handicapped patients; unethical aspects of health promotion; surgical intervention to quieten a very noisy demented old man; what doctors should call their patients; whether or not AIDS could be seen as divine punishment; who should be allowed to donate an organ for transplantation; the alleged "myth" of informed consent; prior discussion with patients about do-not-attempt-resuscitation decisions, and empirical research in medical ethics.

In the 90s, topics of vigorous debates included: commercial surrogate motherhood; the use of quality adjusted life years for ethical decision making; payment for transplant organs; the ventilation of dying patients in order to preserve their organs for transplantation; smokers' rights to health care; treating anorexic patients against their will; "selective reduction" in pregnancy; equipose in medical research; patients holding their own medical records; the role of the market in provision of health care; the proper role of European institutions in biomedical ethics; withdrawal of artificial nutrition and hydration in persistent vegetative state, and in another context, in sedated terminally ill patients; research in psychiatry; use of recently dead patients for teaching and practising medical techniques; the relationship between medical and nursing ethics; the abuse of psychiatry; Australian rejection of the English Bolam doctrine (according to which the views of a reasonable body of medical opinion guide the courts); discrimination between patients on the grounds of their age; covert research in Munchausen syndrome by proxy; the compensation of patients injured in clinical trials; care ethics, virtue ethics and (of course) the four principles approach; the use of "cases" in teaching medical ethics; transplantation of brain tissue; "fetalmaternal conflict"; the selling of blood and other body parts; the need to restore kindness to medical practice; xenotransplantation; cloning; whistleblowing; whether or not doctors should oppose boxing; the ethics of cervical screening practices; ethics and the new genetics and ethics and AIDS/HIV (these were covered in monothematic issues of the journal); a Chinese approach of "protective truthfulness"; compulsory immunisation in childhood; whether medical ethics is of any use; fraud in medical science; parental consent to facia remodelling of their Down's syndrome children; the payment of research subjects; payment to Japanese doctors for obtaining informed consent; approaches to refusal of blood by Jehovah's Witnesses; ethics in biomedical publication; consumerism in prenatal diagnosis, and a debate (from Northern Ireland, let me teasingly add) about the desirability of intolerance.

Are there any discernible developments in medical ethics over the twenty-year period? For me the ever increasing international entrenchment of the four principles of medical ethics as basic to analysis of medical ethics issues is a discernible and highly welcome development - and I can only hope that integration with, rather than the attempted supercession by, other approaches to medical ethics, will be the outcome of current pseudo-battles between "principlism" and, for example, virtue ethics, feminist and feminine ethics, narrative ethics, eco ethics in its various forms, the ethics of different religions, and different geocultural ethics. Appreciation of the strengths of each of the four principles in the development and practice of medical ethics (and indeed of ethics more generally) as well as of their important regulating functions upon each other is discernible and desirable. Thus the primary and ancient Hippocratic moral objective of medicine - to produce net health benefits with minimal harm - still properly drives medicine but is increasingly understood to require tempering by both respect for people's autonomy, and by justice in its various manifestations, especially distributive, rights based and legal. If beneficence and nonmaleficence were the foci of medical ethics in the 1960s and before, with respect for autonomy muscling in front in the $70 \mathrm{~s}$ and $80 \mathrm{~s}$, justice in its various forms, increasingly lumped together as social justice, has begun to raise its hand in the $90 \mathrm{~s}$ and can be predicted to be THE principle for the current decade (including a move towards each other of the human rights "movement" and the bioethics "movement"). Let me add, however, that in 1981 in one of the first issues I edited Tony Smith was suggesting that the principle of worldwide social justice should be an aspect of medical ethics and proposing that doctors should pursue the Willie Brandt line and look at the world as a single community. Eventually, I predict, and certainly hope for, a more inclusive and organic view of these four principles and their interrelationship with each other and with the various other approaches to ethics - as well as badly needed developments in approaches to dealing with conflicts between the principles and in deciding about their proper scope of application.

\section{And an apology}

One major regret is for my own slowness in processing submitted manuscripts - and I seize this valedictory opportunity to apologise to all whom I have kept waiting too long for the assessments of their submitted papers, and indeed for any other correspondence, and to assure them - and all - that my young and efficient and internet-orientated successor will do far better!

I'm enormously proud to have been allowed to edit the journal for the last twenty years: I wish Dr Julian Savulescu as much fun and as much satisfaction in his editorship as I have had in mine. 